\title{
ARTICLE
}

\section{Patterns of Colorectal Cancer Care in the United States: 1990-2010}

\author{
Caitlin C. Murphy, Linda C. Harlan, Jennifer L. Lund, Charles F. Lynch, \\ Ann M. Geiger
}

Affiliations: Department of Epidemiology, University of North Carolina at Chapel Hill, Chapel Hill, NC (CCM, JLL); Healthcare Delivery Research Program, Division of Cancer Control and Population Sciences, National Cancer Institute, Rockville, MD (LCH, AMG); Department of Epidemiology, University of Iowa, Iowa City, IA (CFL).

Correspondence: Caitlin C. Murphy, MPH, Department of Epidemiology, Gillings School of Public Health, University of North Carolina at Chapel Hill, 135 Dauer Drive, 2101 McGavran-Greenberg Hall, CB \#7435, Chapel Hill, NC 27599 (e-mail: caitlin_murphy@med.unc.edu).

\begin{abstract}
Background: Colorectal cancer (CRC) mortality has declined in the United States, in part because of advances in treatment. Few studies have evaluated the adoption of therapies and temporal changes in patterns of care.

Methods: Patients age 20 years and older diagnosed with stages II/III CRC were randomly sampled from the populationbased Surveillance, Epidemiology, and End Results (SEER) program in 1990-1991, 1995, 2000, 2005, and 2010 (n = 7057 ). Therapy was obtained from medical records and physician verification. We described the receipt of chemotherapy and radiation therapy. Log-binomial regression was used to examine factors associated with therapy. All statistical tests were two-sided.
\end{abstract}

Results: Chemotherapy receipt among colon cancer patients increased from 1990 (stage II: 22.5\%; stage III: 56.3\%) to 2005 (stage II: 32.1\%; stage III: 72.4\%) and declined slightly in 2010 (stage II: 29.3\%; stage III: 66.4\%). Stage III colon cancer patients who were older (vs <55 years, 75-79 years: risk ratio [RR] 0.81, 95\% confidence interval $[\mathrm{CI}]=0.71$ to $0.91 ; \geq 80$ years: $\mathrm{RR}=0.37$, $95 \% \mathrm{CI}=0.28$ to 0.47 ) or had a comorbidity score of 2 or higher (vs $0, \mathrm{RR}=0.56,95 \% \mathrm{CI}=0.35$ to 0.87 ) received chemotherapy less often. Receipt of radiation therapy by rectal cancer patients increased across all years from $45.5 \%$ to $66.1 \%$. Increasing age (vs $<55$ years, $75-79$ years: $R R=0.59,95 \% C I=0.47$ to $0.74 ; \geq 80$ years: $R R=0.33,95 \% C I=0.25$ to 0.45 ) was associated with lower chemoradiation use among stage II/III rectal cancer patients.

Conclusion: Our findings demonstrate increased adoption of chemotherapy and radiation therapy for colon and rectal cancer patients and differences in therapy by age, comorbidity, and diagnosis year. Increased receipt of these therapies in the community may further reduce CRC mortality.

The incidence and mortality of colorectal cancer (CRC) have continually declined in the United States over the past two decades. During the years 2001 to 2010, average annual mortality rates were 19.6 and 13.9 per 100000 men and women, respectively. Mortality rates have decreased by $3.0 \%$ per year in both men and women, and the overall five-year relative survival rate has increased from $49.8 \%$ in 1975-1977 to 66.1\% in 2003-2009 (1). Much of the mortality decline has been attributed to screening and advances in treatment (2).
Adjuvant chemotherapy has gained attention as a critical advance in the treatment of colon cancer. Growing evidence suggests several adjuvant chemotherapy regimens markedly improve the overall and disease-free survival of patients with resectable stage III disease (3-8). In contrast, the use of adjuvant therapy for patients with stage II colon cancer remains controversial. Clinical trial results are inconclusive, and many studies show no survival benefit for adjuvant chemotherapy over surgery alone in stage II patients (9). 
The use of preoperative radiation therapy has similarly been recognized as an important advance in the evolution of treatment for locally advanced rectal cancer (stages II and III) (10). Early randomized trials showed the benefit of postoperative radiation in decreasing local recurrence $(11,12)$, but later trials suggested that preoperative radiation therapy also decreases the risk of local recurrence compared with surgery alone $(13,14)$. Although overall survival is similar between patients treated with preoperative and postoperative radiation, preoperative radiation is associated with greater improvements in local control, increased rates of sphincter preservation during surgery, and fewer treatment-induced toxicities (15-17). The addition of chemotherapy to preoperative radiation (ie, chemoradiation) has since been shown to further improve local control and enhance pathological response (18-20).

Few studies have examined the adoption of recommended therapies in community settings as evidence from clinical trials has changed. We aimed to describe receipt of adjuvant chemotherapy among patients diagnosed with stages II and III colon cancer and preoperative and/or postoperative radiation therapy among patients diagnosed with stages II and III rectal cancer. We also assessed the association of receipt of therapy with patient demographic and tumor characteristics.

\section{Methods}

\section{Participants and Procedures}

Patients were sampled from the National Cancer Institute's (NCI's) Surveillance, Epidemiology, and End Results (SEER) program. SEER routinely collects information from hospitals, pathology laboratories, surgical centers, and radiation facilities on patient demographics and tumor characteristics. Preoperative (neoadjuvant) and postoperative (adjuvant) therapies are often underreported in SEER; therefore, the NCI annually conducts patterns of care (POC) studies on a sample of patients with select cancers to assess the extent to which chemotherapy and radiation therapy are received in clinical practice $(21,22)$.

Stages II and III CRC patients in participating SEER registries were eligible for POC studies in 1990-1991, 1995, 2000, 2005, and 2010. Eligible patients were stratified within registries by tumor site (colon or rectum), and a random sample was taken from within each stratum. Beginning in 1995, there was oversampling by race/ethnicity to obtain more stable estimates for these subgroups. Patients were sampled according to the staging scheme used by SEER in each study year. In 1990 or 1991, 1995, and 2000, patients were sampled based on Extent of Disease (EOD) 10 coding, and in 2005 and 2010 patients were sampled based on Collaborative Staging (CS) coding. EOD and CS coding record the farthest extent of disease based on the combined clinical and pathological assessment. Clinical information takes priority when a patient is treated with preoperative therapy; otherwise, pathological information takes priority. TNM staging was derived by mapping $\mathrm{T}$ and $\mathrm{N}$ status from EOD and CS coding. Stage II included T3 or T4 tumors with no positive regional lymph nodes, and stage III included any T1 to T4 tumors with regional lymph node involvement. These stage definitions also correspond approximately to stage B2 and C of the Aster-Coller modification of Duke's original staging system.

Patients were ineligible if they were younger than age 20 years, previously diagnosed with cancer (excluding nonmelanoma skin cancer), diagnosed at autopsy or on death certificate only, or diagnosed with a synchronous cancer. Patients with tumors in the appendix $(n=4)$ or who did not undergo cancerdirected surgery $(n=171)$ were further excluded.
Patients' medical records were abstracted for treatment information, including receipt of specific chemotherapy agents, radiation therapy, and dates of treatment following diagnosis. Because chemotherapy and radiation therapy are often given outside of the hospital setting and SEER data is primarily hospital-based, the treating physician was contacted to verify therapy received or recommended. Treating physicians were also asked to provide names and addresses of other physicians who may have treated the patient, who were subsequently contacted for treatment information. Doctor verification substantially improves completeness of chemotherapy ascertainment or confirms that no chemotherapy or radiation was given. Physician responses were received on more than $85 \%$ of sampled patients.

Comorbid conditions at the time of hospitalization for the most definitive treatment, usually surgery, were abstracted from the medical record. Patient comorbidity was assessed using the Charlson comorbidity index (23).

\section{Analysis}

Weighted proportions and means were used to examine trends in the receipt of adjuvant chemotherapy among stages II and III colon cancer patients and preoperative or postoperative radiation among stages II and III rectal cancer patients. We considered patients who received therapy or were recommended but it was unknown whether they received therapy as having received treatment in the analysis. Patients who refused chemotherapy $(n=148)$ or radiation therapy $(n=26)$ were not considered to have received therapy. We also examined the proportion of patients who received common chemotherapy agents and combination chemotherapy regimens. Although there is a lack of consensus on the use of chemotherapy for stage II colon cancer, we included these patients in select tables. In addition, we examined the proportion of rectal cancer patients who received any chemoradiation (ie, receipt of both chemotherapy and radiation at any point during the course of treatment) and various combinations of multimodality therapy.

Proportions and means were calculated with stratum-specific sample weights to account for the complex survey design. The proportions reported are weighted to reflect the population from which the sample was drawn. Sample weights were calculated as the inverse of the sampling proportion for each sampling stratum.

We used log-binomial regression models with stratum-specific sample weights to explore factors associated with receipt of adjuvant chemotherapy among stage III colon cancer patients and chemoradiation (preoperative or postoperative) among stages II and III rectal cancer patients. Sensitivity analyses considering differential registry participation by year and variation in the receipt of therapy by geographic region did not appreciably affect the results (not shown); therefore, we report the results of the overall analysis. Adjusted associations between covariates and receipt of therapy are reported as risk ratios and $95 \%$ confidence intervals.

Analyses were conducted using SAS version 9.3 (SAS Institute, Cary, NC) and SUDAAN version 11.0.1 (Research Triangle Institute, Raleigh, NC). All statistical tests were two-sided.

\section{Results}

Characteristics of the study population $(n=7057)$ by year of diagnosis are shown in Table 1 . Overall, $28.7 \%$ and $65.4 \%$ of stage II and III colon cancer patients received adjuvant chemotherapy, respectively (Table 2). Chemotherapy use increased among both stages from 1990 or 1991 (stage II: 22.5\%; stage III: 56.3\%) 
Table 1. Characteristics of stages II and III colorectal cancer patients by year of diagnosis $(\mathrm{n}=7057)^{*}$

\begin{tabular}{|c|c|c|c|c|c|}
\hline \multirow[b]{3}{*}{ Characteristics } & \multicolumn{5}{|c|}{ Year of diagnosis } \\
\hline & $\begin{array}{l}1990 / 1991 \\
(\mathrm{n}=2013)\end{array}$ & $\begin{array}{c}1995 \\
(\mathrm{n}=1114)\end{array}$ & $\begin{array}{c}2000 \\
(\mathrm{n}=876)\end{array}$ & $\begin{array}{c}2005 \\
(\mathrm{n}=1602)\end{array}$ & $\begin{array}{c}2010 \\
(\mathrm{n}=1452)\end{array}$ \\
\hline & No. (wt \%) & No. (wt \%) & No. (wt \%) & No. (wt \%) & No. (wt \%) \\
\hline \multicolumn{6}{|l|}{ Sociodemographic characteristics } \\
\hline \multicolumn{6}{|l|}{ Sex } \\
\hline Male & $1087(49.5)$ & $541(48.2)$ & 447 (49.9) & $834(50.5)$ & $731(51.1)$ \\
\hline Female & $926(50.5)$ & $573(51.8)$ & $429(50.1)$ & $768(49.5)$ & $721(48.9)$ \\
\hline Age at diagnosis, mean (SD), y & $70.0(0.30)$ & $69.2(0.59)$ & $69.3(0.60)$ & $67.2(0.61)$ & $66.5(0.60)$ \\
\hline$<55$ & $254(10.4)$ & $186(13.8)$ & $188(13.6)$ & 419 (19.9) & $395(21.0)$ \\
\hline $55-64$ & $406(18.0)$ & $246(19.0)$ & $187(20.8)$ & $366(20.4)$ & $345(23.7)$ \\
\hline $65-74$ & $671(33.8)$ & $341(30.0)$ & $237(27.0)$ & $369(23.9)$ & $339(21.5)$ \\
\hline $75-79$ & $287(15.3)$ & $149(15.4)$ & $105(13.0)$ & $185(14.7)$ & $144(11.4)$ \\
\hline$\geq 80$ & 395 (22.5) & 192 (21.9) & $159(25.6)$ & $263(21.1)$ & $229(22.4)$ \\
\hline \multicolumn{6}{|l|}{ Race/ethnicity } \\
\hline White non-Hispanic & $1731(87.6)$ & $564(81.1)$ & $329(73.2)$ & $568(70.7)$ & $466(68.0)$ \\
\hline Black non-Hispanic & $163(7.3)$ & $273(10.8)$ & $197(9.1)$ & $351(9.9)$ & $356(9.8)$ \\
\hline Hispanic & $64(2.7)$ & $277(8.1)$ & $168(8.1)$ & $324(10.3)$ & $301(12.7)$ \\
\hline Other & $55(2.3)$ & 0 & $182(9.6)$ & $359(9.0)$ & $329(9.4)$ \\
\hline \multicolumn{6}{|l|}{ Health insurance } \\
\hline Private/HMO/VA/Other & $1520(75.1)$ & $782(74.6)$ & $539(66.2)$ & $1047(73.0)$ & $910(65.6)$ \\
\hline Medicaid & $74(3.5)$ & $115(6.2)$ & $137(9.9)$ & $246(10.2)$ & $310(16.8)$ \\
\hline Medicare & $315(17.1)$ & $149(13.0)$ & 147 (19.5) & $228(14.5)$ & $147(11.9)$ \\
\hline None & $31(1.4)$ & $38(2.8)$ & $32(2.2)$ & $65(1.7)$ & $69(3.9)$ \\
\hline Unknown & $73(2.9)$ & $30(3.3)$ & $21(2.2)$ & $16(0.6)$ & $16(1.8)$ \\
\hline \multicolumn{6}{|l|}{ Marital status } \\
\hline Married & $1232(57.7)$ & $611(55.1)$ & $477(55.0)$ & $876(50.6)$ & $749(53.2)$ \\
\hline Not married $\dagger$ & $744(40.3)$ & $485(43.1)$ & $368(42.0)$ & $692(47.4)$ & $639(42.5)$ \\
\hline Unknown & $37(2.0)$ & $18(1.8)$ & $31(3.0)$ & 34 (1.9) & $64(4.3)$ \\
\hline \multicolumn{6}{|l|}{ Comorbidity score } \\
\hline 0 & $1507(74.1)$ & $776(70.6)$ & $666(74.0)$ & $1132(70.1)$ & $963(66.7)$ \\
\hline 1 & $408(20.9)$ & $274(25.0)$ & $163(21.0)$ & $373(23.5)$ & $386(26.2)$ \\
\hline$\geq 2$ & $98(5.0)$ & $64(4.5)$ & $47(5.0)$ & $97(6.4)$ & $103(7.1)$ \\
\hline \multicolumn{6}{|l|}{ Tumor characteristics } \\
\hline \multicolumn{6}{|l|}{ Site } \\
\hline Colon & $1080(77.4)$ & $631(77.6)$ & 494 (75.2) & $920(72.8)$ & $740(71.4)$ \\
\hline Rectum $\neq$ & $933(22.6)$ & $483(22.4)$ & $382(24.8)$ & $682(27.2)$ & $712(28.6)$ \\
\hline \multicolumn{6}{|l|}{ Stage§ } \\
\hline II & $974(58.7)$ & $564(55.5)$ & $372(40.7)$ & $829(50.9)$ & $723(49.1)$ \\
\hline III & $1039(41.3)$ & $550(44.5)$ & $504(59.3)$ & $773(49.1)$ & $729(50.9)$ \\
\hline $\begin{array}{l}\text { Number of positive lymph nodes } \\
\text { (stage III only), mean (SD) }\end{array}$ & $3.2(0.10)$ & $3.6(0.23)$ & $3.6(0.24)$ & $3.5(0.19)$ & $3.2(0.19)$ \\
\hline \multicolumn{6}{|l|}{ Histologic grade } \\
\hline Well differentiated & $176(8.6)$ & $55(6.9)$ & $43(5.2)$ & $94(8.5)$ & $70(4.8)$ \\
\hline Moderately differentiated & $1328(66.3)$ & $796(67.0)$ & $599(65.7)$ & $1133(66.0)$ & $1037(71.5)$ \\
\hline Poorly differentiated & 354 (17.1) & $217(21.9)$ & $194(25.0)$ & $289(21.6)$ & $232(17.2)$ \\
\hline Undifferentiated & $17(1.0)$ & $8(1.2)$ & $8(1.1)$ & $20(1.6)$ & $46(3.3)$ \\
\hline Unknown & $138(7.0)$ & $38(3.0)$ & $32(2.9)$ & $66(2.3)$ & $63(3.2)$ \\
\hline \multicolumn{6}{|l|}{ Clinical trial participation } \\
\hline No & $1461(75.6)$ & $805(76.5)$ & $846(96.1)$ & $1471(88.5)$ & $1407(96.4)$ \\
\hline Yes & $165(7.0)$ & $49(3.0)$ & $20(3.1)$ & $76(4.9)$ & $11(0.5)$ \\
\hline Unknown & $387(17.4)$ & $260(20.4)$ & $10(0.9)$ & $55(6.6)$ & $34(3.1)$ \\
\hline
\end{tabular}

* Percentages and means weighted by sampling fraction. Missing or unknown values included in proportions. wt $=$ weighted. $\dagger$ Not married includes single, divorced, separated, and widowed.

‡ Rectum includes tumors in the rectum or rectosigmoid junction.

§ Patients diagnosed in 1990 or 1991, 1995, and 2000 were sampled based on Extent of Disease (EOD) 10 coding, and patients diagnosed in 2005 and 2010 were sampled based on Collaborative Staging (CS) coding. TNM staging was derived by mapping T and N status from EOD and CS coding. Stage II included T3 or T4 tumors with no positive regional lymph nodes, and stage III included any T1 to T4 tumors with regional lymph node involvement. Stage definitions also correspond approximately to stage B2 and C of the Aster-Coller modification of Duke's original staging system.

to 2005 (stage II: $32.1 \%$; stage III: $72.4 \%$ ) and slightly decreased in 2010 (stage II: 29.3\%; stage III: 66.4\%). Receipt differed by age at diagnosis among stage II patients, with increases in receipt of therapy between 1990 or 1991 and 2000 in the 55 to 64 and 65 to 74 year age groups (Supplementary Figure 1, available online). There were also differences in receipt of adjuvant chemotherapy 
Table 2. Proportion of stages II and III colon cancer patients who received adjuvant chemotherapy by stage at diagnosis $(\mathrm{n}=3757)^{*}$

\begin{tabular}{|c|c|c|c|c|}
\hline \multirow[b]{3}{*}{ Characteristics } & \multicolumn{4}{|c|}{ Proportion of patients receiving chemotherapy } \\
\hline & \multicolumn{2}{|c|}{ Stage II $(\mathrm{n}=1908)$} & \multicolumn{2}{|c|}{ Stage III $(\mathrm{n}=1849)$} \\
\hline & wt \% & $95 \%$ CI & wt $\%$ & $95 \%$ CI \\
\hline Overall & 28.7 & 25.4 to 32.3 & 65.4 & 61.8 to 68.9 \\
\hline \multicolumn{5}{|l|}{ Year of diagnosis } \\
\hline 1990/1991 & 22.5 & 19.0 to 26.4 & 56.3 & 51.0 to 61.4 \\
\hline 1995 & 27.9 & 21.2 to 35.6 & 59.5 & 48.6 to 69.6 \\
\hline 2000 & 33.5 & 24.4 to 44.2 & 65.3 & 56.2 to 73.4 \\
\hline 2005 & 32.1 & 24.8 to 40.5 & 72.4 & 65.1 to 78.7 \\
\hline 2010 & 29.3 & 21.8 to 38.2 & 66.4 & 58.2 to 73.7 \\
\hline \multicolumn{5}{|l|}{ Age at diagnosis, $\mathrm{y}$} \\
\hline$<55$ & 59.5 & 48.6 to 69.5 & 84.5 & 78.6 to 89.0 \\
\hline $55-64$ & 46.2 & 38.4 to 54.2 & 84.9 & 79.3 to 89.2 \\
\hline $65-74$ & 29.9 & 23.9 to 36.6 & 72.9 & 65.4 to 79.3 \\
\hline $75-79$ & 17.3 & 11.3 to 25.4 & 63.0 & 54.0 to 71.2 \\
\hline$\geq 80$ & 5.8 & 3.6 to 9.0 & 30.3 & 21.9 to 40.3 \\
\hline \multicolumn{5}{|l|}{ Race/ethnicity } \\
\hline White non-Hispanic & 28.1 & 23.9 to 32.6 & 65.5 & 60.8 to 70.0 \\
\hline Black non-Hispanic & 28.8 & 23.5 to 34.8 & 60.8 & 54.8 to 66.6 \\
\hline Hispanic & 34.4 & 27.3 to 42.3 & 65.0 & 54.7 to 74.1 \\
\hline Other & 29.8 & 23.0 to 37.6 & 71.0 & 62.1 to 78.6 \\
\hline \multicolumn{5}{|l|}{ Health insurance } \\
\hline Private/HMO/VA/Other & 31.2 & 26.9 to 35.7 & 67.0 & 62.7 to 71.1 \\
\hline Medicaid & 24.2 & 15.8 to 35.2 & 61.4 & 51.8 to 70.2 \\
\hline Medicare & 18.5 & 12.6 to 26.3 & 57.9 & 47.7 to 67.5 \\
\hline None & 43.3 & 28.0 to 60.0 & 73.6 & 55.2 to 86.3 \\
\hline Unknown & 39.9 & 19.8 to 64.2 & 76.0 & 50.6 to 90.7 \\
\hline \multicolumn{5}{|l|}{ Comorbidity score } \\
\hline 0 & 31.5 & 27.4 to 36.0 & 68.5 & 64.3 to 72.4 \\
\hline 1 & 23.1 & 17.2 to 30.4 & 64.0 & 56.5 to 70.9 \\
\hline$\geq 2$ & 16.8 & 7.2 to 34.2 & 33.6 & 22.0 to 47.6 \\
\hline \multicolumn{5}{|l|}{ Tumor extent } \\
\hline T1-2 & NA & NA & 76.9 & 66.9 to 84.5 \\
\hline T3 & 24.8 & 21.7 to 28.3 & 65.4 & 61.4 to 69.2 \\
\hline $\mathrm{T} 4$ & 53.6 & 41.7 to 65.2 & 58.0 & 47.6 to 67.8 \\
\hline \multicolumn{5}{|l|}{ Histologic grade } \\
\hline Well/moderately differentiated & 28.7 & 25.4 to 32.3 & 67.1 & 62.8 to 71.2 \\
\hline Poorly/undifferentiated & 27.3 & 20.2 to 35.7 & 61.2 & 53.7 to 68.2 \\
\hline Unknown & 37.6 & 24.2 to 53.2 & 65.0 & 49.8 to 77.6 \\
\hline \multicolumn{5}{|l|}{ Positive margins at surgery } \\
\hline Yes & 49.1 & 27.7 to 70.8 & 53.8 & 36.9 to 69.8 \\
\hline No & 28.3 & 24.7 to 32.2 & 66.5 & 62.8 to 69.9 \\
\hline Unknown & 24.7 & 17.4 to 33.9 & 62.2 & 47.1 to 75.3 \\
\hline
\end{tabular}

* Proportions weighted by sampling fraction. Table excludes patients who did not undergo cancer-directed surgery $(\mathrm{n}=20)$ or with missing or unknown chemotherapy agents $(n=82)$; patients who received preoperative chemotherapy $(n=6)$ are included. $\mathrm{CI}=$ confidence interval; $\mathrm{NA}=$ not applicable; $\mathrm{wt}=\mathrm{weighted}$.

for stage III patients by age and comorbidity (Figure 1). Receipt was highest among younger age groups (age $<55$ years, $84.5 \%$; age 55-64 years, $84.9 \%$ ) and patients with a comorbidity score of $0(68.5 \%)$. A substantially smaller proportion of patients over the age of 80 years received chemotherapy in all study years (Supplementary Figure 2, available online).

Among stage III patients who received chemotherapy, there was a rapid increase in the use of oxaliplatin $(5.5 \%$ in 2000 to $78.1 \%$ in 2010 ) and capecitabine (3.0\% in 2000 to $23.6 \%$ in 2010 ), with a parallel decrease in the use of any 5-FU (98.8\% in 1990 or 1991 to $79.3 \%$ in 2010) (Table 3). The majority of patients diagnosed in 1990 or 1991 (56.4\%) and 1995 (53.3\%) received 5-FU and levamisole, whereas patients diagnosed in 2010 were predominantly treated with FOLFOX (72.6\%). A growing number of patients were treated with capecitabine alone (12.1\% in 2010) or in combination with oxaliplatin (ie, CapeOx) (4.3\% in 2010).
The proportion of stages II and III rectal cancer patients who received any radiation therapy (preoperative or postoperative) increased from $45.5 \%$ in 1990 or 1991 to $66.1 \%$ in 2010 (Figure 2). Receipt of any radiation therapy was higher among younger patients (age $<55$ years, $74.4 \%$ ) compared with older patients (age $\geq 80$ years, $25.1 \%$ ) and among patients with a comorbidity score of $0(60.4 \%)$ compared with patients with a comorbidity score of 2 or higher (53.4\%). During the study period, $31.6 \%$ of patients received postoperative radiation therapy and $27.3 \%$ received preoperative radiation (Table 4). Receipt of preoperative radiation substantially increased over time, from $2.8 \%$ in 1990 or 1991 to $47.3 \%$ in 2010 . The proportion of patients who received postoperative radiation increased from 1990 or 1991 (42.7\%) to 1995 (51.3\%) and subsequently decreased through 2010 (18.8\%).

Receipt of chemoradiation for rectal cancer increased from $37.2 \%$ in 1990 or 1991 to $66.6 \%$ in 2010 (Supplementary Figure 3, 


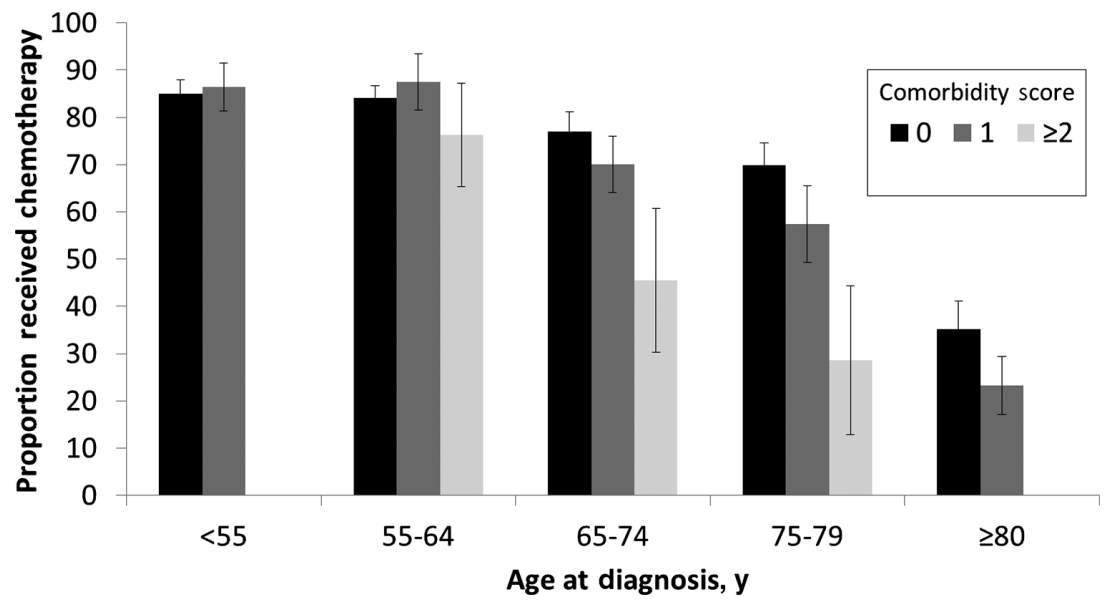

Figure 1. Proportion of stage III colon cancer patients diagnosed between 1990 and 2010 who received adjuvant chemotherapy by comorbidity score and age at diagnosis $(\mathrm{n}=1849)$. Proportions weighted by sampling fraction. Figure excludes patients who did not undergo cancer-directed surgery ( $\mathrm{n}=9$ ) or with missing or unknown chemotherapy agents $(n=82)$. Comorbidity score $(C S)$ greater than 2 not shown for ages $<55$ and $\geq 80$ years because of small number of observations $(n<5)$.

Table 3. Receipt of select chemotherapy agents and combination chemotherapy among stage III colon cancer patients treated with adjuvant chemotherapy by year of diagnosis $(\mathrm{n}=1205)$ (not mutually exclusive categories) ${ }^{*}$

\begin{tabular}{|c|c|c|c|c|c|}
\hline \multirow[b]{3}{*}{ Chemotherapy agent (any) } & \multicolumn{5}{|c|}{ Year of diagnosis } \\
\hline & $\begin{array}{c}1990 / 1991 \\
(\mathrm{n}=286)\end{array}$ & $\begin{array}{c}1995 \\
(\mathrm{n}=185)\end{array}$ & $\begin{array}{c}2000 \\
(\mathrm{n}=162)\end{array}$ & $\begin{array}{c}2005 \\
(\mathrm{n}=306)\end{array}$ & $\begin{array}{c}2010 \\
(\mathrm{n}=266)\end{array}$ \\
\hline & wt \% & wt $\%$ & wt $\%$ & wt $\%$ & wt \% \\
\hline 5-FU & 98.8 & 99.9 & 96.9 & 88.6 & 79.3 \\
\hline Leucovorin & 33.1 & 42.9 & 87.1 & 83.9 & 77.4 \\
\hline Levamisole & 70.5 & 73.3 & 2.3 & 3.9 & 0.6 \\
\hline Bevacizumab & $\dagger$ & $\dagger$ & $\dagger$ & 16.1 & 6.3 \\
\hline Capecitabine & $\dagger$ & $\dagger$ & 3.0 & 15.5 & 23.6 \\
\hline Cetuximab & $\dagger$ & $\dagger$ & $\dagger$ & 5.5 & 1.5 \\
\hline Irinotecan & $\dagger$ & $\dagger$ & 8.0 & 10.1 & 6.1 \\
\hline Oxaliplatin & $\dagger$ & $\dagger$ & 5.5 & 69.0 & 78.1 \\
\hline Other $\neq$ & 6.9 & 2.0 & 6.2 & 7.6 & 4.1 \\
\hline \multicolumn{6}{|l|}{ Chemotherapy regimen } \\
\hline 5-FU alone & 8.6 & 2.8 & 8.2 & 2.1 & 1.3 \\
\hline 5-FU + leucovorin (only) & 17.4 & 22.7 & 76.3 & 17.6 & 4.7 \\
\hline 5-FU + levamisole (only) & 56.4 & 53.3 & 0 & 0 & 0 \\
\hline FOLFOX (any) & $\dagger$ & $\dagger$ & 5.5 & 62.9 & 72.6 \\
\hline FOLFIRI (any) & $\dagger$ & $\dagger$ & 7.5 & 9.6 & 4.7 \\
\hline Capecitabine alone & $\dagger$ & $\dagger$ & 0.2 & 3.6 & 12.1 \\
\hline CapeOx (only) & $\dagger$ & $\dagger$ & 0 & 3.1 & 4.3 \\
\hline
\end{tabular}

${ }^{*}$ Proportions weighted by sampling fraction and not mutually exclusive. 5 -FU = 5-fluorouracil; CapeOx = capecitabine + oxaliplatin; FOLFIRI = 5-FU + leucovorin + irinotecan; FOLFOX = 5-FU + leucovorin + oxaliplatin; wt = weighted.

† No patient in our dataset received bevacizumab, cetuximab, capectiabine, irinotecan, or oxaliplatin in these years.

‡ Other includes less frequently administered chemotherapy agents, including methyl CCNU, CCNU, vincristine, PALA, UFT, methotrexate, and BCNU.

available online); however, the sequencing of radiation and chemotherapy differed by year of diagnosis (Table 5). The use of surgery followed by postoperative chemoradiation increased from $35.2 \%$ in 1990 or 1991 to $45.1 \%$ in 1995 and decreased from $2000(41.6 \%)$ to $2010(18.7 \%)$. The proportion of patients who received preoperative chemoradiation followed by surgery increased over the study period. From 2005 to 2010, the receipt of preoperative chemoradiation followed by surgery and postoperative chemotherapy nearly doubled (11.2\% in 2005 to $20.8 \%$ in 2010). Among chemotherapy treated patients (preoperative, postoperative, or both), the use of 5-FU alone decreased from $38.3 \%$ in 1990 or 1991 to $10.3 \%$ in 2010, and there was an increase in the use of capectiabine alone $(0.5 \%$ in 2000 to $20.8 \%$ in 2010) (Table 5). Similarly, the proportion of patients who received FOLFOX increased from 2005 (32.3\%) to 2010 (44.0\%).

In the log-binomial regression models, being diagnosed in year 2000 (risk ratio $[R R]=1.17,95 \%$ confidence interval [CI $=1.03$ to 1.34$), 2005(R R=1.26,95 \% \mathrm{CI}=1.15$ to 1.39$)$, and 2010 $(\mathrm{RR}=1.24,95 \% \mathrm{CI}=1.12$ to 1.37$)$ was associated with receipt of chemotherapy among stage III colon cancer patients compared with being diagnosed in 1990 or 1991 (Table 6). Increasing age (75-79 years: $R R=0.81,95 \% C I=0.71$ to $0.91 ; \geq 80$ years: $R R=0.37$, $95 \% \mathrm{CI}=0.28$ to 0.47$)$, black ( $R R=0.80,95 \% \mathrm{CI}=0.71$ to 0.91$)$ and Hispanic ( $R R=0.80,95 \% \mathrm{CI}=0.67$ to 0.97 ) race/ethnicity, and a 


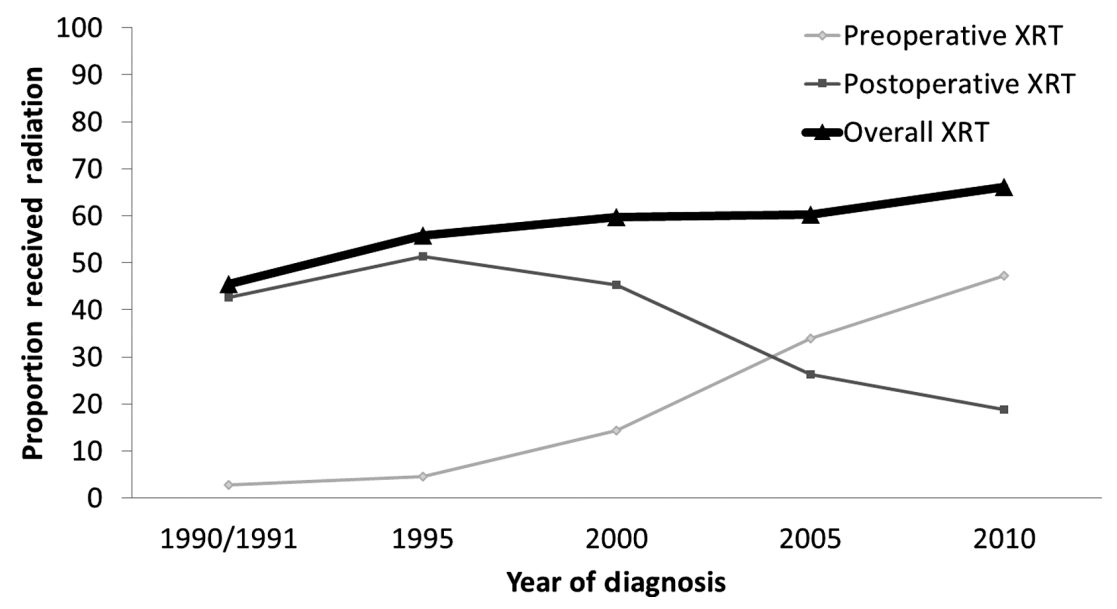

Figure 2. Proportion of stages II and III rectal cancer patients who received preoperative or postoperative radiation therapy by year of diagnosis $(\mathrm{n}=3016)$. Proportions weighted by sampling fraction. Figure excludes patients who did not undergo cancer-directed surgery $(n=145)$, received intraoperative radiation $(n=1)$, received both preoperative and postoperative radiation $(n=15)$, and those in whom a radiation sequence could not be determined $(n=13)$. XRT $=$ radiation therapy.

comorbidity score of 2 or greater $(\mathrm{RR}=0.56,95 \% \mathrm{CI}=0.35$ to 0.87) were associated with not receiving chemotherapy. Among stages II and III rectal cancer patients, being diagnosed in 1995 $(\mathrm{RR}=1.36,95 \% \mathrm{CI}=1.17$ to 1.58$), 2000(\mathrm{RR}=1.40,95 \% \mathrm{CI}=1.19$ to 1.65$), 2005$ ( $R R=1.40,95 \% C I=1.21$ to 1.63 ) or 2010 ( $R R=1.59$, $95 \% \mathrm{CI}=1.38$ to 1.84 ) was associated with receipt of any chemoradiation (preoperative or postoperative) compared with being diagnosed in 1990 or 1991 (Table 6). Increasing age (65-74 years: $\mathrm{RR}=0.87,95 \% \mathrm{CI}=0.78$ to $0.98 ; 75-79$ years: $\mathrm{RR}=0.59,95 \%$ $\mathrm{CI}=0.47$ to $0.74 ; \geq 80$ years: $\mathrm{RR}=0.33,95 \% \mathrm{CI}=0.25$ to 0.45 ) was associated with not receiving chemoradiation.

\section{Discussion}

Our results demonstrate that receipt of adjuvant chemotherapy for colon cancer gradually increased starting in 1990, which coincides with the publication of major findings from large, randomized trials (4) and recommendations of the National Institutes of Health Consensus Conference (3). Consistent with guidelines (24-28), the majority of stage III patients in our study received chemotherapy, but there were some marked disparities by age and comorbidity. As noted by others, older patients and those with high comorbidity are less likely to receive chemotherapy (29-34). Some physicians may not endorse adjuvant therapy for select patients because the expected gains in overall survival do not outweigh the potential harms to quality of life. Older patients and those with multiple comorbidities may not wish to pursue aggressive treatment. Further, there may be uncertainty regarding appropriate treatment strategies for older patients because they have historically been excluded from clinical trials (35).

Despite the uncertainty of evidence surrounding the use of adjuvant chemotherapy for stage II colon cancer, stage II patients frequently received chemotherapy during the study period. Almost one-third of all stage II patients, and more than $60 \%$ of younger patients ( $<55$ years) with stage II disease, were treated with chemotherapy. These results are consistent with other studies that suggest that a large proportion of stage II colon cancer patients receive chemotherapy (30,36-39) and that receipt differs by age and comorbidity $(29,30,36,37)$. Although some early trials have suggested a similar reduction in risk of recurrence for stage II and III patients treated with chemotherapy (40-42), past and current guidelines recommend against chemotherapy for stage II disease $(3,24-28)$, based on cumulative evidence from meta-analyses $(9,43)$. The proportion of stage II patients treated with chemotherapy in our study may be a result of both overtreatment of normal-risk and appropriate treatment of high-risk patients. Stage II patients with high-risk features (eg, T4 tumors, poorly differentiated histology, lymphovascular invasion) can be considered for adjuvant therapy, and we observed a larger proportion of stage II patients with T4 tumors or positive surgical margins treated with chemotherapy. However, only a small minority of stage II patients who received chemotherapy could be classified as high-risk. Our findings support the need for additional trials to identify subgroups of stage II colon cancer patients who are most likely to benefit from adjuvant chemotherapy.

Our results also highlight the rapid diffusion of newer therapies into community settings. Nearly $80 \%$ of all chemotherapy-treated patients with stage III colon cancer received oxaliplatin in 2010, compared with just $5 \%$ in 2000 . This increase corresponds to a shift in evidence in favor of adding adjuvant oxaliplatin to 5-FU and its approval by the US Food and Drug Administration in 2004. Results of the Multicenter International Study of Oxaliplatin/5-Fluorouracil/Leucovorin (MOSAIC) trial showed an additional $23 \%$ reduction in risk of recurrence among patients treated with FOLFOX compared with those treated with 5 -FU and leucovorin alone $(8,44)$. The increased use of oxaliplatin in our study also highlights contemporary controversy regarding the use of therapy in older patients. Although the MOSAIC trial and numerous other studies (45-48) support the use of oxaliplatin for stage III colon cancer, only a small proportion of patients enrolled in these trials were older than 70 years. More recently, studies suggest there is little or no survival benefit of adjuvant oxaliplatin for older patients $(49,50)$, and current guidelines $(25)$ recommend against routine use in these patients ( $>70$ years). However, the increasing use of oxaliplatin observed in our study, combined with the findings of others (51), may suggest oxaliplatin is still widely used in this population subgroup. Because uncertainty remains regarding the role of oxaliplatin in older patients, careful consideration must be given to the potential survival benefit in conjunction with patient preferences, cost, and risk of adverse events.

Similarly, we observed an increase in the use of capecitabine, either alone or in combination with oxaliplatin, from 2000 through 2010. Capecitabine was approved as an oral alternative 
Table 4. Proportion of stages II and III rectal cancer patients who received preoperative or postoperative radiation therapy $(\mathrm{n}=3016)^{*}$

\begin{tabular}{|c|c|c|c|c|}
\hline \multirow[b]{3}{*}{ Characteristics } & \multicolumn{4}{|c|}{ Proportion of patients receiving therapy } \\
\hline & \multicolumn{2}{|c|}{ Postoperative radiation } & \multicolumn{2}{|c|}{ Preoperative radiation } \\
\hline & wt \% & $95 \%$ CI & wt \% & $95 \%$ CI \\
\hline Overall & 31.6 & 29.1 to 34.1 & 27.3 & 24.7 to 30.0 \\
\hline \multicolumn{5}{|l|}{ Stage } \\
\hline II & 27.6 & 24.4 to 31.1 & 27.2 & 23.6 to 31.1 \\
\hline III & 34.8 & 31.2 to 38.5 & 27.3 & 23.7 to 31.2 \\
\hline \multicolumn{5}{|l|}{ Year of diagnosis } \\
\hline $1990 / 1991$ & 42.7 & 39.3 to 46.2 & 2.8 & 1.7 to 4.5 \\
\hline 1995 & 51.3 & 46.4 to 56.3 & 4.6 & 2.9 to 7.2 \\
\hline 2000 & 45.3 & 37.3 to 53.4 & 14.4 & 10.4 to 19.6 \\
\hline 2005 & 26.3 & 21.5 to 31.8 & 33.8 & 27.9 to 40.4 \\
\hline 2010 & 18.8 & 14.6 to 23.9 & 47.3 & 41.7 to 52.9 \\
\hline \multicolumn{5}{|l|}{ Age at diagnosis, y } \\
\hline$<55$ & 30.6 & 25.9 to 35.7 & 43.8 & 37.7 to 50.2 \\
\hline $55-64$ & 36.1 & 30.4 to 42.1 & 29.9 & 24.9 to 35.5 \\
\hline $65-74$ & 35.0 & 30.5 to 39.8 & 24.8 & 20.3 to 29.8 \\
\hline $75-79$ & 30.4 & 23.3 to 38.6 & 15.7 & 10.0 to 23.9 \\
\hline$\geq 80$ & 18.6 & 12.8 to 26.2 & 6.5 & 3.8 to 10.8 \\
\hline \multicolumn{5}{|l|}{ Race/ethnicity } \\
\hline White non-Hispanic & 32.5 & 29.4 to 35.8 & 25.3 & 22.1 to 28.8 \\
\hline Black non-Hispanic & 31.0 & 26.4 to 36.0 & 29.7 & 25.1 to 34.7 \\
\hline Hispanic & 29.2 & 24.0 to 34.9 & 33.0 & 27.3 to 39.2 \\
\hline Other & 26.5 & 21.5 to 32.1 & 36.1 & 29.9 to 42.7 \\
\hline \multicolumn{5}{|l|}{ Health insurance } \\
\hline Private/HMO/VA/Other & 33.0 & 30.2 to 36.0 & 27.3 & 24.2 to 30.7 \\
\hline Medicaid & 25.5 & 18.6 to 33.8 & 36.0 & 28.2 to 44.6 \\
\hline Medicare & 27.5 & 21.3 to 34.6 & 22.0 & 15.7 to 29.9 \\
\hline None & 31.0 & 17.9 to 48.1 & 24.1 & 12.7 to 40.9 \\
\hline Unknown & 33.9 & 22.9 to 47.0 & 6.9 & 2.0 to 21.2 \\
\hline \multicolumn{5}{|l|}{ Comorbidity score } \\
\hline 0 & 31.3 & 28.4 to 34.4 & 29.1 & 25.8 to 32.5 \\
\hline 1 & 30.8 & 25.9 to 36.2 & 24.5 & 20.1 to 29.4 \\
\hline$\geq 2$ & 37.9 & 27.0 to 50.3 & 15.5 & 7.5 to 29.3 \\
\hline \multicolumn{5}{|l|}{ Chemotherapy $\dagger$} \\
\hline Yes & 40.5 & 37.3 to 43.8 & 37.7 & 34.4 to 41.2 \\
\hline No & 10.2 & 8.0 to 12.9 & 1.8 & 1.1 to 2.9 \\
\hline Unknown & 6.6 & 2.8 to 14.6 & 5.9 & 2.1 to 15.1 \\
\hline
\end{tabular}

* Proportions weighted by sampling fraction. Proportions combine across rows for total number of patients who received any radiation therapy. Table excludes patients who did not undergo cancer-directed surgery $(n=145)$, received intraoperative radiation $(n=1)$, received both preoperative and postoperative radiation $(n=17)$, and those in which a radiation sequence could not be determined $(n=13)$. CI = confidence interval; wt = weighted .

$\uparrow$ Chemotherapy includes any chemotherapy received preoperatively, postoperatively, or both.

to 5-FU after phase III trial data showed equivalent diseasefree survival, improved relapse-free survival, and fewer adverse events when comparing oral capecitabine to 5-FU and leucovorin (7). Our data provide support for a substitution effect, whereby the number of patients treated with capecitabine increased as the use of 5-FU simultaneously decreased. Capecitabine use has traditionally been difficult to measure on a population level because it is frequently underreported in Medicare claims data (52). This may be because claims data capture drug dispensing that generates a claim for reimbursement and do not capture information on prescribing. Differences between prescribing and dispensing may occur when patients decide not to fill the drug prescribed. One possibility is that patients with high copayments either do not fill capecitabine prescriptions (53) or receive the drug through pharmacy assistance programs, both of which are not captured in claims data. Given the limitations of administrative data sources, continuing to monitor treatment dispensing with capecitabine will likely remain a challenge. The unique features of our study design, particularly physician verification of therapy receipt, allowed us to provide a populationbased estimate of capecitabine use.

While adjuvant chemotherapy for stage III colon cancer has been universally recommended by guidelines since 1990, the sequence and combination of therapies for rectal cancer have evolved over time and are reflected in our analysis. The proportion of patients who received preoperative radiation surpassed the proportion who received postoperative radiation in 2005 . Also in 2005, patients treated with preoperative chemoradiation (with or without postoperative chemotherapy) exceeded the proportion treated with postoperative chemoradiation. These changes parallel results of the landmark German trial published in 2004 (15) that showed preoperative chemoradiation decreased the risk of local recurrence, improved sphincter preservation, and decreased treatment-related toxicities compared with postoperative therapy. Although earlier trials $(13,14,17)$ and treatment guidelines (24) advocated preoperative therapy to 
Table 5. Sequence of therapy and receipt of select chemotherapy agents among stages II and III rectal cancer patients by year of diagnosis $(\mathrm{n}=3000)$ (mutually exclusive categories)*

\begin{tabular}{|c|c|c|c|c|c|}
\hline \multirow[b]{3}{*}{ Therapy sequence } & \multicolumn{5}{|c|}{ Year of diagnosis } \\
\hline & $\begin{array}{c}1990 / 1991 \\
(\mathrm{n}=911)\end{array}$ & $\begin{array}{c}1995 \\
(\mathrm{n}=462)\end{array}$ & $\begin{array}{c}2000 \\
(\mathrm{n}=356)\end{array}$ & $\begin{array}{c}2005 \\
(\mathrm{n}=630)\end{array}$ & $\begin{array}{c}2010 \\
(\mathrm{n}=641)\end{array}$ \\
\hline & wt \% & wt $\%$ & wt \% & wt \% & wt \% \\
\hline Surgery alone & 38.8 & 30.4 & 24.4 & 20.1 & 18.5 \\
\hline Surgery + postoperative radiation & 7.0 & 4.7 & 3.0 & 2.2 & 0.3 \\
\hline Surgery + postoperative chemotherapy & 12.5 & 12.2 & 14.3 & 17.8 & 13.6 \\
\hline Surgery + postoperative chemoradiation & 35.2 & 45.1 & 41.6 & 24.2 & 18.7 \\
\hline Preoperative chemoradiation + surgery & 0.9 & 3.8 & 13.3 & 22.8 & 24.2 \\
\hline Preoperative chemoradiation + surgery + postoperative chemotherapy & $\dagger$ & $\dagger$ & $\dagger$ & 11.2 & 20.8 \\
\hline \multicolumn{6}{|l|}{ Chemotherapy agents $\ddagger$} \\
\hline 5-FU alone & 38.3 & 35.3 & 35.8 & 16.5 & 10.3 \\
\hline 5-FU + leucovorin (only) & 23.3 & 31.5 & 53.9 & 14.3 & 3.5 \\
\hline 5-FU + levamisole (only) & 25.3 & 14.9 & 1.1 & 0 & 0 \\
\hline FOLFOX (any) & $\dagger$ & $\dagger$ & 0 & 32.3 & 44.0 \\
\hline FOLFIRI (any) & $\dagger$ & $\dagger$ & 5.1 & 3.3 & 6.3 \\
\hline Capecitabine alone & $\dagger$ & $\dagger$ & 0.5 & 10.7 & 20.8 \\
\hline CapeOx (only) & $\dagger$ & $\dagger$ & 0 & 6.1 & 5.9 \\
\hline
\end{tabular}

${ }^{*}$ Proportions weighted by sampling fraction. Percentages do not add to 100 because of infrequently administered treatment sequences (eg, preoperative radiation + surgery). Table excludes patients who did not undergo cancer-directed surgery $(n=145)$ and with unknown or missing chemotherapy agents $(n=47)$. Patients with unknown or missing dates of chemotherapy or surgery $(n=25)$ and unknown radiation and surgery sequence $(n=9)$ are excluded from the proportions of therapy sequences, including chemotherapy or radiation. 5-FU $=5$-fluorouracil; CapeOx $=$ capecitabine + oxaliplatin; FOLFIRI $=5$-FU + leucovorin + irinotecan; FOLFOX $=5$-FU + leucovorin + oxaliplatin; $\mathrm{wt}=$ weighted.

† Preoperative chemoradiation + surgery + postoperative chemotherapy not measured, and no patient in our dataset received FOLFOX, FOLFIRI, capecitabine, and CapeOx in these years.

₹ Chemotherapy agents limited to patients who received any chemotherapy $(n=2039)$ and include chemotherapy delivered preoperatively, postoperatively, or both.

decrease the volume of the primary tumor, our results suggest that clinical practices did not shift toward preoperative treatment until after 2000.

The large increase in the proportion of rectal cancer patients treated with preoperative chemoradiation followed by surgery and postoperative chemotherapy in our study reflects the controversy surrounding the use of postoperative chemotherapy in this population. Although US guidelines advocate for the addition of postoperative chemotherapy to preoperative chemoradiation and surgery $(54,55)$, some randomized trials reported no survival benefit (56-59). Long-term results of the EORTC 22921 trial suggested no difference in 10-year overall survival for patients treated with preoperative chemoradiation and postoperative chemotherapy compared with those treated with preoperative chemoradiation and surgery (56). However, a recent trial demonstrated improved disease-free survival with postoperative FOLFOX among rectal cancer patients treated with preoperative chemoradiation and surgery $(60)$. Other studies $(61,62)$ suggested that many rectal cancer patients treated with preoperative chemoradiation do not complete postoperative chemotherapy for reasons of age, performance status, pathological response, or surgical complications. Regardless of patient ability to tolerate additional therapy or response to preoperative treatment, the effect of postoperative chemotherapy remains unclear among patients previously treated with preoperative chemoradiation.

The differences we observed in the receipt of therapy for rectal cancer compared with colon cancer patients underscore inherent differences in the clinical behavior and treatment of these two distinct cancers. There was some difference in receipt of therapy by age and comorbidity for rectal cancer, but it was not as pronounced as the differences for colon cancer. For example, our results suggest a $30 \%$ difference in the proportion of stage III colon cancer patients with a comorbidity of 0 and greater than 2 who received chemotherapy compared with a difference of approximately $10 \%$ among rectal cancer patients receiving any radiation therapy. We also observed a lower receipt of adjuvant chemotherapy for black and Hispanic colon cancer patients compared with whites, but there was no racial disparity in chemoradiation receipt among rectal cancer patients. The modality of rectal cancer treatment changed frequently during the study period, and differential receipt of therapy by race may have been masked by changing treatment paradigms. In addition, although colon and rectal cancer share many features, there is an increased risk of local recurrence among rectal cancer patients. Preventing recurrence is a primary goal of therapy, which may explain why a larger number of older, high comorbidity, and minority rectal cancer patients received therapy.

Our study has several strengths. Patients were sampled by tumor site, sex, and age and oversampled by race/ethnicity to ensure adequate sample sizes that supported analyses by a variety of covariates. Detailed treatment information was available, including specific chemotherapy agents and treatment dates, which were verified by treating physicians and/or medical record review. Our results also complement randomized studies of treatment efficacy by demonstrating how changes in community practice have paralleled shifts in evidence from clinical trials.

A limitation of our analysis is the inability to fully explain trends and patterns of care observed during the study period that may be because of patient preferences or changes in healthcare delivery. For example, there was an overall decrease in the receipt of therapy among both colon and rectal cancer patients in 2010 that is likely not a result of differences in patient age or comorbidity. The decrease in therapy may instead be because of the increasing costs of CRC care $(53,63-67)$ and the impact of the 2008 economic recession (eg, changes in insurance coverage, 
Table 6. Adjusted risk ratios for the receipt of therapy among stage III colon and stages II and III rectal cancer patients $(\mathrm{n}=4849)^{*}$

\begin{tabular}{|c|c|c|}
\hline \multirow[b]{2}{*}{ Variables } & \multirow{2}{*}{$\begin{array}{l}\text { Receipt of adjuvant chemotherapy } \\
\text { for stage III colon cancer }(n=1849) \\
\text { Adjusted } \neq \text { RR }(95 \% \text { CI })\end{array}$} & \multirow{2}{*}{$\begin{array}{c}\text { Receipt of chemoradiation } \dagger \\
\text { for stages II and III rectal cancer }(\mathrm{n}=3000) \\
\text { Adjusted } \mathrm{RR}(95 \% \mathrm{CI})\end{array}$} \\
\hline & & \\
\hline \multicolumn{3}{|l|}{ Year of diagnosis } \\
\hline 1990/1991 & 1.00 & 1.00 \\
\hline 1995 & 1.07 (0.91 to 1.27 ) & 1.36 (1.17 to 1.58$)$ \\
\hline 2000 & 1.17 (1.03 to 1.34 ) & 1.40 (1.19 to 1.65$)$ \\
\hline 2005 & $1.26(1.15$ to 1.39$)$ & 1.40 (1.21 to 1.63$)$ \\
\hline 2010 & 1.24 (1.12 to 1.37$)$ & 1.59 (1.38 to 1.84$)$ \\
\hline \multicolumn{3}{|l|}{ Age at diagnosis, y } \\
\hline$<55$ & 1.00 & 1.00 \\
\hline $55-64$ & 1.03 (0.95 to 1.11$)$ & 0.93 (0.84 to 1.04$)$ \\
\hline $65-74$ & 0.89 (0.76 to 1.03 ) & 0.87 (0.78 to 0.98$)$ \\
\hline $75-79$ & 0.81 (0.71 to 0.91$)$ & 0.59 (0.47 to 0.74$)$ \\
\hline$\geq 80$ & 0.37 (0.28 to 0.47 ) & $0.33(0.25$ to 0.45$)$ \\
\hline \multicolumn{3}{|l|}{ Race/ethnicity } \\
\hline White non-Hispanic & 1.00 & 1.00 \\
\hline Black non-Hispanic & 0.80 (0.71 to 0.91$)$ & 0.98 (0.89 to 1.07$)$ \\
\hline Hispanic & 0.80 (0.67 to 0.97$)$ & 0.98 (0.87 to 1.11$)$ \\
\hline Other & 0.92 (0.84 to 1.02$)$ & 1.00 (0.92 to 1.15$)$ \\
\hline \multicolumn{3}{|l|}{ Comorbidity score } \\
\hline 0 & 1.00 & 1.00 \\
\hline 1 & 1.00 (0.96 to 1.04$)$ & 0.96 (0.87 to 1.06$)$ \\
\hline$\geq 2$ & 0.56 (0.35 to 0.87$)$ & 0.92 (0.75 to 1.13$)$ \\
\hline \multicolumn{3}{|l|}{ Health insurance } \\
\hline Private/HMO/VA/Other & 1.00 & 1.00 \\
\hline Medicaid & 0.95 (0.83 to 1.09$)$ & 1.03 (0.92 to 1.15$)$ \\
\hline Medicare & 0.98 (0.87 to 1.11$)$ & 1.07 (0.92 to 1.24$)$ \\
\hline None/unknown & 0.99 (0.88 to 1.12$)$ & 0.79 (0.58 to 1.09$)$ \\
\hline \multicolumn{3}{|l|}{ Stage } \\
\hline II & & 1.00 \\
\hline III & & 1.09 (0.99 to 1.20$)$ \\
\hline
\end{tabular}

* Stage III colon cancer analysis excludes patients who did not undergo cancer-directed surgery $(n=9)$ or with missing or unknown chemotherapy agents $(n=82)$; stage II/III rectal cancer analysis excludes patients who did not undergo cancer-directed surgery $(n=145)$ or with unknown or missing chemotherapy agents $(n=47)$. $\mathrm{CI}=$ confidence interval; $\mathrm{RR}=$ risk ratio.

† Chemoradiation includes both chemotherapy and radiation therapy delivered in the preoperative or postoperative setting. ‡ Adjusted for all other variables shown in the table.

copays, or cost sharing), which are not captured in the data. We also did not have a measure of performance status. Comorbidity score may account for some of the differences we observed in receipt of therapy, but performance status may further explain these differences. Finally, rates of physician verification were lower in 1990 or 1991 and 1995 than in other study years. We considered patients for whom therapy was recommended but it was unknown whether therapy was received as having received treatment in the analysis. Although there were few of these cases, our results may be slightly overestimated.

In summary, multiple randomized trials have demonstrated the efficacy of adjuvant therapies in improving the overall and disease-free survival of patients with locally advanced colorectal cancer. Our findings demonstrate increased adoption of adjuvant therapies for both colon and rectal cancer patients and differences in receipt of therapy by age, comorbidity, and year of diagnosis. Ongoing use of these therapies in community settings is critical to further reducing CRC mortality.

\section{Funding}

Grant Support: National Institutes of Health Grant T32 DK07634 (C. C. Murphy).
National Cancer Institute Contracts: HHSN261201300019I, HHSN261201300005I, HHSN261201300011I, HHSN261201300015I, HHSN261201300014I, HHSN261201300009I, HHSN261201300020I, HHSN261201300013I, HHSN261201300004I, HHSN261201300016I, HHSN261201300021I, HHSN261201300010I, HHSN261201300012I, HHSN261201300017I.

\section{Notes}

The authors would like to acknowledge Dr. Hanna Sanoff for her thoughtful review of the manuscript.

The authors have no conflicts of interest to disclose.

\section{References}

1. Siegel R, Desantis C, Jemal A. Colorectal cancer statistics, 2014. CA Cancer J Clin. 2014;64(2):104-117.

2. Edwards BK, Ward E, Kohler BA, et al. Annual report to the nation on the status of cancer, 1975-2006, featuring colorectal cancer trends and impact of interventions (risk factors, screening, and treatment) to reduce future rates. Cancer. 2010;116(3):544-573.

3. NIH Consensus Conference. Adjuvant therapy for patients with colon and rectal cancer. JAMA. 1990;264(11):1444-1450.

4. Moertel CG, Fleming TR, Macdonald JS, et al. Levamisole and fluorouracil for adjuvant therapy of resected colon carcinoma. N Engl J Med. 1990;322(6):352358. 
5. Haller DG, Catalano PJ, Macdonald JS, et al. Phase III study of fluorouracil, leucovorin, and levamisole in high-risk stage II and III colon cancer: final report of Intergroup 0089. J Clin Oncol. 2005;23(34):8671-8678.

6. Schmoll HJ, Cartwright T, Tabernero J, et al. Phase III trial of capecitabine plus oxaliplatin as adjuvant therapy for stage III colon cancer: a planned safety analysis in 1,864 patients. J Clin Oncol. 2007;25(1):102-109.

7. Twelves C, Wong A, Nowacki MP, et al. Capecitabine as adjuvant treatment for stage III colon cancer. N Engl J Med. 2005;352(26):2696-2704.

8. Andre T, Boni C, Mounedji-Boudiaf L, et al. Oxaliplatin, fluorouracil, and leucovorin as adjuvant treatment for colon cancer. $N$ Engl J Med. 2004;350(23):2343-2451.

9. Benson AB, 3rd, Schrag D, Somerfield MR, et al. American Society of Clinical Oncology recommendations on adjuvant chemotherapy for stage II colon cancer. J Clin Oncol. 2004;22(16):3408-3419.

10. Wong RK, Tandan V, De Silva S, et al. Pre-operative radiotherapy and curative surgery for the management of localized rectal carcinoma. Cochrane Database Syst Rev. 2007;CD002102.

11. Fisher B, Wolmark N, Rockette H, et al. Postoperative adjuvant chemotherapy or radiation therapy for rectal cancer: results from NSABP protocol R-01. J Natl Cancer Inst. 1988;80(1):21-29.

12. Thomas PR, Lindblad AS. Adjuvant postoperative radiotherapy and chemotherapy in rectal carcinoma: a review of the Gastrointestinal Tumor Study Group experience. Radiother Oncol. 1988;13(4):245-252.

13. Improved survival with preoperative radiotherapy in resectable rectal cancer. Swedish Rectal Cancer Trial. N Engl J Med. 1997;336(14):980-987.

14. Kapiteijn E, Marijnen CA, Nagtegaal ID, et al. Preoperative radiotherapy combined with total mesorectal excision for resectable rectal cancer. $N$ Engl $J$ Med. 2001;345(9):638-646.

15. Sauer R, Becker H, Hohenberger W, et al. Preoperative versus postoperative chemoradiotherapy for rectal cancer. N Engl J Med. 2004;351(17):1731-1740.

16. Sauer R, Liersch T, Merkel S, et al. Preoperative versus postoperative chemoradiotherapy for locally advanced rectal cancer: results of the German CAO/ ARO/AIO-94 randomized phase III trial after a median follow-up of 11 years. J Clin Oncol. 2012;30(16):1926-1933.

17. Wagman R, Minsky BD, Cohen AM, et al. Sphincter preservation in rectal cancer with preoperative radiation therapy and coloanal anastomosis: long term follow-up. Int J Radiat Oncol Biol Phys. 1998;42(1):51-57.

18. Gerard JP, Conroy T, Bonnetain F, et al. Preoperative radiotherapy with or without concurrent fluorouracil and leucovorin in T3-4 rectal cancers: results of FFCD 9203. J Clin Oncol. 2006;24(28):4620-4625.

19. Bosset JF, Collette L, Calais G, et al. Chemotherapy with preoperative radiotherapy in rectal cancer. N Engl J Med. 2006;355(11):1114-1123.

20. McCarthy K, Pearson K, Fulton R, et al. Pre-operative chemoradiation for non-metastatic locally advanced rectal cancer. Cochrane Database Syst Rev. 2012;12:CD008368.

21. Cronin DP, Harlan LC, Potosky AL, et al. Patterns of care for adjuvant therapy in a random population-based sample of patients diagnosed with colorectal cancer. Am J Gastroenterol. 2006;101(10):2308-2318.

22. Potosky AL, Harlan LC, Kaplan RS, et al. Age, sex, and racial differences in the use of standard adjuvant therapy for colorectal cancer. J Clin Oncol. 2002;20(5):1192-1202.

23. Charlson ME, Pompei P, Ales KL, et al. A new method of classifying prognostic comorbidity in longitudinal studies: development and validation. J Chronic Dis. 1987;40(5):373-383.

24. Benson AB, 3rd, Choti MA, Cohen AM, et al. NCCN Practice Guidelines for Colorectal Cancer. Oncology (Williston Park). 2000;14(11A):203-212.

25. Benson AB, 3rd, Venook AP, Bekaii-Saab T, et al. Colon cancer, version 3.2014. J Natl Compr Canc Netw. 2014;12(7):1028-1059.

26. Engstrom PF, Arnoletti JP, Benson AB, 3rd, et al. NCCN Clinical Practice Guidelines in Oncology: colon cancer. J Natl Compr Canc Netw. 2009;7(8):778-831.

27. Engstrom PF, Benson AB, 3rd, Chen YJ, et al. Colon cancer clinical practice guidelines in oncology. J Natl Compr Canc Netw. 2005;3(4):468-491.

28. Engstrom PF, Benson AB, 3rd, Cohen A, et al. NCCN Colorectal Cancer Practice Guidelines. The National Comprehensive Cancer Network. Oncology (Williston Park). 1996;10(11 Suppl):140-175.

29. Hardiman KM, Cone M, Sheppard BC, et al. Disparities in the treatment of colon cancer in octogenarians. Am J Surg. 2009;197(5):624-628.

30. Quah HM, Joseph R, Schrag D, et al. Young age influences treatment but not outcome of colon cancer. Ann Surg Oncol. 2007;14(10):2759-2765.

31. Luo R, Giordano SH, Freeman JL, et al. Referral to medical oncology: a crucial step in the treatment of older patients with stage III colon cancer. Oncologist. 2006;11(9):1025-1033.

32. Neugut AI, Matasar M, Wang X, et al. Duration of adjuvant chemotherapy for colon cancer and survival among the elderly. J Clin Oncol. 2006;24(15):23682375.

33. Sundararajan V, Mitra N, Jacobson JS, et al. Survival associated with 5-fluorouracil-based adjuvant chemotherapy among elderly patients with nodepositive colon cancer. Ann Intern Med. 2002;136(5):349-357.

34. Schrag D, Cramer LD, Bach PB, et al. Age and adjuvant chemotherapy use after surgery for stage III colon cancer. J Natl Cancer Inst. 2001;93(11):850-857.

35. Hutchins LF, Unger JM, Crowley JJ, et al. Underrepresentation of patients 65 years of age or older in cancer-treatment trials. N Engl J Med. 1999;341(27):2061-2067.
36. Kirkpatrick HM, Aitelli CL, Qin H, et al. Referral patterns and adjuvant chemotherapy use in patients with stage II colon cancer. Clin Colorectal Cancer. 2010;9(3):150-156.

37. Earle CC, Weiser MR, Ter Veer A, et al. Effect of lymph node retrieval rates on the utilization of adjuvant chemotherapy in stage II colon cancer. J Surg Oncol. 2009;100(7):525-528.

38. Wirtzfeld DA, Mikula L, Gryfe R, et al. Concordance with clinical practice guidelines for adjuvant chemotherapy in patients with stage I-III colon cancer: experience in 2 Canadian provinces. Can J Surg. 2009;52(2):92-97.

39. Schrag D, Rifas-Shiman S, Saltz L, et al. Adjuvant chemotherapy use for Medicare beneficiaries with stage II colon cancer. J Clin Oncol. 2002;20(19):39994005.

40. Mamounas E, Wieand S, Wolmark N, et al. Comparative efficacy of adjuvant chemotherapy in patients with Dukes' B versus Dukes' C colon cancer: results from four National Surgical Adjuvant Breast and Bowel Project adjuvant studies (C-01, C-02, C-03, and C-04). J Clin Oncol. 1999;17(5):13491355.

41. Taal BG, Van Tinteren H, Zoetmulder FA. Adjuvant 5FU plus levamisole in colonic or rectal cancer: improved survival in stage II and III. $\mathrm{Br} J$ Cancer. 2001;85(10):1437-1443.

42. Wolmark N, Rockette H, Mamounas E, et al. Clinical trial to assess the relative efficacy of fluorouracil and leucovorin, fluorouracil and levamisole, and fluorouracil, leucovorin, and levamisole in patients with Dukes' B and C carcinoma of the colon: results from National Surgical Adjuvant Breast and Bowel Project C-04. J Clin Oncol. 1999;17(11):3553-3559.

43. Figueredo A, Charette ML, Maroun J, et al. Adjuvant therapy for stage II colon cancer: a systematic review from the Cancer Care Ontario Program in evidence-based care's gastrointestinal cancer disease site group. J Clin Oncol. 2004;22(16):3395-3407.

44. Andre T, Boni C, Navarro M, et al. Improved overall survival with oxaliplatin, fluorouracil, and leucovorin as adjuvant treatment in stage II or III colon cancer in the MOSAIC trial. J Clin Oncol. 2009;27(19):3109-3116.

45. Mack CD, Carpenter W, Meyer AM, et al. Racial disparities in receipt and comparative effectiveness of oxaliplatin for stage III colon cancer in older adults. Cancer. 2012;118(11):2925-2934

46. Kuebler JP, Wieand HS, O'Connell MJ, et al. Oxaliplatin combined with weekly bolus fluorouracil and leucovorin as surgical adjuvant chemotherapy for stage II and III colon cancer: results from NSABP C-07. J Clin Oncol. 2007;25(16):2198-2204.

47. Sanoff HK, Carpenter WR, Martin CF, et al. Comparative effectiveness of oxaliplatin vs non-oxaliplatin-containing adjuvant chemotherapy for stage III colon cancer. J Natl Cancer Inst. 2012;104(3):211-227.

48. Yothers G, O'Connell MJ, Allegra CJ, et al. Oxaliplatin as adjuvant therapy for colon cancer: updated results of NSABP C-07 trial, including survival and subset analyses. J Clin Oncol. 2011;29(28):3768-3774.

49. McCleary NJ, Meyerhardt JA, Green E, et al. Impact of age on the efficacy of newer adjuvant therapies in patients with stage II/III colon cancer: findings from the ACCENT database. J Clin Oncol. 2013;31(20):2600-2606.

50. McCleary NJ, Odejide O, Szymonifka J, et al. Safety and effectiveness of oxaliplatin-based chemotherapy regimens in adults 75 years and older with colorectal cancer. Clin Colorectal Cancer. 2013;12(1):62-69.

51. Lund JL, Sturmer T, Sanoff HK, et al. Determinants of adjuvant oxaliplatin receipt among older stage II and III colorectal cancer patients. Cancer. 2013;119(11):2038-2047.

52. Lund JL, Sturmer T, Harlan LC, et al. Identifying specific chemotherapeutic agents in Medicare data: a validation study. Med Care. 2013;51(5):e27e34.

53. Shankaran V, Jolly S, Blough D, Ramsey SD. Risk factors for financial hardship in patients receiving adjuvant chemotherapy for colon cancer: a populationbased exploratory analysis. J Clin Oncol. 2012;30(14):1608-1614.

54. Benson AB, 3rd, Bekaii-Saab T, Chan E, et al. Rectal cancer. J Natl Compr Canc Netw. 2012;10(12):1528-1564.

55. Petersen SH, Harling H, Kirkeby LT, et al. Postoperative adjuvant chemotherapy in rectal cancer operated for cure. Cochrane Database Syst Rev. 2012;3:CD004078.

56. Bosset JF, Calais G, Mineur L, et al. Fluorouracil-based adjuvant chemotherapy after preoperative chemoradiotherapy in rectal cancer: long-term results of the EORTC 22921 randomised study. Lancet Oncol. 2014;15(2):184190

57. Cionini L, Sainato A, De Paoli A. Final results of randomized trial on adjuvant chemotherapy after preoperative chemoradiation in rectal cancer. Radiother Oncol. 2010;96(Suppl 1):S113-S114.

58. Breugom A, van der Broek C, van Gijn W, et al. The value of adjuvant chemotherapy in rectal cancer patients after preoperative radiotherapy or chemoradiation followed by TME-surgery: The PROCTOR/SCRIPT study. Eur J Cancer. 2013;49(Suppl 3):S1.

59. Glynne-Jones R, Counsell N, Meadows H, et al. A phase III trial in locally advanced rectal cancer after neoadjuvant chemoradiation randomising postoperative adjuvant capecitabine/oxaliplatin versus control. Ann Oncol. 2013;24(Suppl 4):iv18-iv18.

60. Hong YS, Nam BH, Kim KP, et al. Adjuvant chemotherapy with oxaliplatin/5fluorouracil/leucovorin (FOLFOX) versus 5-fluorouracil/leucovorin (FL) for rectal cancer patients whose postoperative yp stage 2 or 3 after preoperative 
chemoradiotherapy: updated results of 3-year disease-free survival from a randomized phase II study (The ADORE). J Clin Oncol. 2014;32(5s):Suppl; Abstr 3502.

61. Khrizman P, Niland JC, ter Veer A, et al. Postoperative adjuvant chemotherapy use in patients with stage II/III rectal cancer treated with neoadjuvant therapy: a national comprehensive cancer network analysis. J Clin Oncol. 2013;31(1):30-38.

62. Haynes AB, You YN, Hu CY, et al. Postoperative chemotherapy use after neoadjuvant chemoradiotherapy for rectal cancer: Analysis of Surveillance, Epidemiology, and End Results-Medicare data, 1998-2007. Cancer. 2014;120(8):1162-1170.

63. Kent EE, Forsythe LP, Yabroff KR, et al. Are survivors who report cancerrelated financial problems more likely to forgo or delay medical care? Cancer. 2013;119(20):3710-3717.
64. Ramsey S, Blough D, Kirchhoff A, et al. Washington State cancer patients found to be at greater risk for bankruptcy than people without a cancer diagnosis. Health Aff (Millwood). 2013;32(6):1143-1152.

65. Yabroff KR, Lund J, Kepka D, Mariotto A. Economic burden of cancer in the United States: estimates, projections, and future research. Cancer Epidemiol Biomarkers Prev. 2011;20(10):2006-2014.

66. Guy GP Jr, Ekwueme DU, Yabroff KR, et al. Economic burden of cancer survivorship among adults in the United States. J Clin Oncol. 2013;31(30):37493757.

67. Ekwueme DU, Yabroff KR, Guy GP Jr, et al. Medical costs and productivity losses of cancer survivors--United States, 2008-2011. MMWR Morb Mortal Wkly Rep. 2014;63(23):505-510. 